\title{
Fungal Inoculum Properties: Extracellular Enzyme Expression and Pentachlorophenol Removal in Highly Contaminated Field Soils
}

\author{
Christopher I. Ford, Monika Walter, ${ }^{*}$ and Grant L. Northcott HortResearch \\ Hong J. Di and Keith C. Cameron Lincoln University \\ Tania Trower HortResearch
}

This study was conducted to improve the pentachlorophenol (PCP) bioremediation ability of white-rot fungi in highly contaminated field soils by manipulating bioaugmentation variables. These were the dry weight percentage of fungal inoculum addition (31-175 $\left.\mathrm{g} \mathrm{kg}^{-1}\right)$, PCP concentration (100$2137 \mathrm{mg} \mathrm{kg}^{-1} \mathrm{PCP}$ ), fungal inoculum formulation, and time (17 wk). Five fungal isolates were used: the New Zealand isolates Trametes versicolor (L.: Fr.) HR131 and Trametes sp. HR577; the North American isolates Phanerochaete chrysosporium Burds. (two isolates) and Phanerochaete sordida (Karst.) Erikss. \& Ryv. Pentachlorophenol removal, manganese peroxidase, and laccase activity, and the formation of chloroanisoles in the contaminated field soils were measured. The majority of PCP removed by the Trametes isolates was in the first week after bioaugmentation. The maximum PCP removal by the fungi varied from 50 to $65 \%$ from a $1065 \mathrm{mg} \mathrm{kg}^{-1} \mathrm{PCP}$ contaminated field soil. Pentachlorophenol was preferentially converted to pentachloroanisole (PCA) by the Phanerochaete isolates $(>60 \%)$, while 2 to $9 \%$ of the PCP removed by two Trametes isolates was converted to PCA. A pH increase was measured following bioaugmentation that was dependent on PCP concentration, fungal inoculum addition, and formulation. This, together with rapid initial PCP removal, possibly changed the bioavailability of the remaining PCP to the fungi and significantly decreased the sequestering of PCP in the contaminated field soils. The research supports the conclusion that New Zealand Trametes spp. can rapidly remove PCP in contaminated field soils. Bioavailability and extractability of PCP in the contaminated field soil may significantly increase after bioaugmentation.

Copyright $\odot 2007$ by the American Society of Agronomy, Crop Science Society of America, and Soil Science Society of America. All rights reserved. No part of this periodical may be reproduced or transmitted in any form or by any means, electronic or mechanical, including photocopying, recording, or any information storage and retrieval system, without permission in writing from the publisher.

Published in J. Environ. Qual. 36:1599-1608 (2007).

doi:10.2134/jeq2007.0149

Received 25 Mar. 2007.

*Corresponding author (mwalter@hortresearch.co.nz).

(c) ASA, CSSA, SSSA

677 S. Segoe Rd., Madison, WI 53711 USA
$\mathrm{P}$ ENTACHLOROPHENOL (PCP) has been used as a fungicide in the New Zealand timber industry since 1950 and there are an estimated 800 PCP-contaminated timber treatment sites throughout New Zealand (Sazbo, 1993). Pentachlorophenol is reported as a probable human carcinogen by the USEPA and persists in the environment, with a reported half-life of up to $5 \mathrm{yr}$ (NTP, 1999). In New Zealand, PCP residue levels can be as high as $35 \mathrm{~g} \mathrm{PCP} \mathrm{kg}^{-1}$ soil as a direct result of timber treatment from 1950 to 1990 (Walter et al., 2005b). These high residue levels have undergone little change during the last $10 \mathrm{yr}$ (Walter et al., 2007), probably because of aging. Aging of persistent organic pollutants can retard biodegradation rates and produce what is called "hockey stick kinetics" (Alexander, 1999). There is initial rapid biodegradation of the compound in question, and then the biodegradation rate slows down or is stopped completely because the remainder of the xenobiotic has been sequestered, in some form, and is unavailable for biodegradation (Northcott and Jones, 2000). Hydrophobic organic chemicals mainly sequester on or into the soil organic matter and can involve diffusion of the compound into soil micropores and nanopores, sorption into soil organic matter, covalent bonding (i.e., oxidative coupling), hydrogen bonding or complexing of some description. The sequestering process is time dependent and some aged residues can be up to fifty years old (Luthy et al., 1997; Alexander, 1999; Northcott and Jones, 2000). Not all of these processes are undesirable. For instance, oxidative coupling is regarded as beneficial, because the polymerization or covalent bonding process can render the xenobiotic biologically inactive (RüttimannJohnson and Lamar, 1996, 1997).

White-rot fungi (Basidomycetes) are forest-dwelling organisms that play a major role in the global carbon cycle by being some of

C.I. Ford and M. Walter, Environment and Risk Management Group, The Horticulture and Food Research Inst. of New Zealand Ltd. (HortResearch), P.O. Box 51, Lincoln, New Zealand; G.L. Northcott and T. Trower, Quality Systems, HortResearch, Ruakura, Private Bag 3123, Hamilton, New Zealand; H.J. Di and K.C. Cameron, Centre for Soil and Environmental Quality, P.O. Box 94, Lincoln Univ., Canterbury, New Zealand. Technology New Zealand Enterprise Scholarship No LINX03008.

Abbreviations: $\mathrm{C} / \mathrm{N}$, carbon to nitrogen ratio; $\mathrm{ECD}$, electron capture detector; $\mathrm{F} 2$, Monterey pine sawdust-cornmeal starch formulation; F8, Monterey pine (Pinus radiata D. Don) sawdust-kibbled rye- $\mathrm{CaCO}_{3}$ formulation; F15, Douglas fir [Pseudotsuga menziesii Mirbel (Franco)] sawdust-corn grits formulation; GC, gas chromatography; IANZ, International Accreditation New Zealand; MnP, manganese peroxidase; MS, mass spectroscopy; LSD, least significant difference; NTP, National Toxicology Program; PCA, pentachloroanisole; $\mathrm{PCP}$, pentachlorophenol; REML, restricted maximum likelihood; SAFI, co-substrate amendment and fungal inocula; SED, standard error of difference in means; $U$, one international unit of enzyme. 
the few organisms that can degrade wood lignin. The extracellular enzymes that make this possible are nonspecific and these enzymes can be used to degrade a wide range of persistent organic pollutants (Bumpus and Aust, 1985). Therefore, bioremediation technologies (specifically bioaugmentation: the growth of foreign microorganisms under favorable conditions for inoculation into the contaminated medium) have been developed that make use of these properties for the cleanup of timber treatment facilities where PCP was used. White-rot fungi require co-substrate addition for growth and survival in the contaminated soil as they are not native to this environment (Lamar and Dietrich, 1990b).

The amount of fungal inoculum for bioaugmentation into contaminated soils typically ranges from 30 to $250 \mathrm{~g} \mathrm{~kg}^{-1}$ on a dry weight basis of colonized fungal inoculum to soil (Lamar and Dietrich, 1990b; Lamar et al., 1993a, 1993b; Morgan et al., 1993; Leštan et al., 1996; Leštan and Lamar, 1996; Walter et al., 2005a, 2005b). Subsequently, the lower fungal inoculum values yielded less PCP bioremediation, especially above PCP concentrations of $1000 \mathrm{mg} \mathrm{kg}^{-1}$ for both aged residue and spiked PCP.

Pentachlorophenol removal rate data for a preliminary study (Walter et al., 2005a) using New Zealand white-rot fungi was reported as $5.3 \mathrm{mg} \mathrm{kg}^{-1} \mathrm{~d}^{-1}$. However, the fungal growth substrate used had a high $\mathrm{C} / \mathrm{N}$ ratio (293:1), a low fungal inoculum loading rate ( $30 \mathrm{~g} \mathrm{~kg}^{-1}$ dry wt.), and the fungal inoculum was in stationary phase culture $(21 \mathrm{~d})$. Later work demonstrated that a lower $\mathrm{C} / \mathrm{N}$ ratio (50:1), higher fungal inoculum loading (103 and $175 \mathrm{~g} \mathrm{~kg}^{-1}$ dry wt.), and younger culture age removed significantly more PCP from a contaminated field soil with similar characteristics (Ford et al., 2007). Accordingly, PCP biodegradation rate data require investigation, for these new fungal inoculum loading rates, culture ages, and formulation.

There is more than one PCP degradation pathway and Phanerochaete chrysosporium Burds. and Phanerochaete sordida (Karst.) Erikss. \& Ryv. are reported to promote preferentially a PCP methylation reaction to pentachloroanisole (PCA) as part of its fungal PCP mineralization pathway (Lamar et al., 1990, 1993b; Walter et al., 2004). This is catalyzed by a transmembrane methyl transferase, in P. chrysosporium not an extracellular enzyme (Aust et al., 2004). A wide variety of microorganisms promote this transformation as a general microbial detoxification response to PCP (Laine and Jorgensen, 1996). However, PCA is more hydrophobic than PCP and therefore has the potential to bio-accumulate, which makes its production undesirable (Laine and Jorgensen, 1996). There are also reports of PCA production from PCP biodegradation by Trametes versicolor (L.: Fr.) (Tuomela et al., 1999; Walter et al., 2004). However, the PCA levels produced from $T$. versicolor biodegradation of PCP are typically $<10 \%$ of the total PCP degraded, in contrast to $P$. chrysosporium where $>50 \%$ of PCP degraded can be converted to PCA (Walter et al., 2004). A majority of these white-rot fungal PCP degradation pathway studies were either conducted in vitro or in PCP-spiked soils rather than aged residues from contaminated timber treatment sites (Rüttimann-Johnson and Lamar, 1997; Tuomela et al., 1999; Walter et al., 2004). Therefore, levels of PCA produced by white-rot fungal biodegradation processes of aged residues also require analysis.
The objectives of this study were initially to determine the effects of fungal inoculum loading and PCP concentration in the contaminated field soil on fungal extracellular enzyme expression and PCP removal after bioaugmentation, and in addition, to investigate the fungal PCP biodegradation rate in a $\sim 1050 \mathrm{mg} \mathrm{kg}^{-1}$ PCP-contaminated field soil (Ford et al., 2007) and the PCA production over 7 wk for two New Zealand Trametes isolates and compare this with two cataloged North American P. chrysosporium isolates (ATCC 24725 and ATCC 3541) and one P. sordida isolate (ATCC 90628).

\section{Materials and Methods}

\section{Materials}

The American white-rot fungi, Phanerochaete chrysosporium (ATCC 3541) and Phanerochaete sordida (ATCC 90628), were purchased, whereas Phanerochaete chrysosporium (ATCC 24725) was gifted by Professor Stephen Aust, Utah State University, Logan, UT. The New Zealand white-rot fungal isolates Trametes versicolor HR131, and a Trametes sp. HR577, were supplied by HortResearch, Lincoln. All fungi were grown on malt extract agar (Merck, Darmstadt, Germany) at $26 \pm 2{ }^{\circ} \mathrm{C}$ in the dark for 6 to $7 \mathrm{~d}$. Isolates were maintained in $20 \%$ glycerol (BioLab, Clayton, VIC, Australia) on $1.0 \mathrm{~cm}$ diam. malt extract agar plugs, stored at $-80^{\circ} \mathrm{C}$ (Walter et al., 2003). All chemicals used were of analytical grade. Acetone, hexane, phosphoric acid, methanol, heptane (Mallinckrodt), and calcium carbonate (BDH) were supplied by Biolab New Zealand Ltd. Technical grade pentachlorophenol was supplied by Sigma Chemical Company (St. Louis, MO, USA). The Douglas fir [Pseudotsuga menziesii Mirbel (Franco)] and Monterey pine (Pinus radiata D. Don) sawdusts used for fungal inocula production were sourced fresh from a local sawmill in the Canterbury region. Sawdusts were air-dried, sieved (2.8 mm aperture, BS410, serial No. 081815) and stored in the dark at room temperature. Corn grits (320 mesh), kibbled rye, and corn meal starch were obtained from a local bulk store retail outlet (Bin Inn). The field soil contaminated with technical grade PCP (aged PCP residue) was obtained from a disturbed environment at a sawmill in the Bay of Plenty region in the North Island of New Zealand. The characteristics of the technical grade PCP-contaminated field soil were reported in a previous publication (Ford et al., 2007). The dilution soil to produce "the PCP soil mix" was a Temuka clay loam ("clay loam”) from Lincoln, New Zealand as described by Walter et al. (2004). The spectrophotometer for the enzyme assays was a Cary 50 Bio UV/VIS spectrophotometer (Varian Australia Pty Ltd).

\section{Methods}

The methodology for growth of the fungi for bioaugmentation and subsequent production of the soil microcosms is outlined in a previous publication (Ford et al., 2007). Briefly, the contaminated field soil was sieved ( 4.00 or $2.80-\mathrm{mm}$ sieve) and diluted with an air-dried clay loam of the same sieve size to enhance fungal survival. This PCP-soil mix was then hydrated and mixed with the co-substrate amendment and fungal inoculum (SAFI). This ratio of co-substrate amendment and fungal inoculum (the "SAFI 
ratio") was varied in the different experiments. The soil microcosm control cultures consisted of mixing $135 \mathrm{~g}$ of co-substrate amendment (no fungal inoculum) with the PCP-soil mix and measuring the PCP concentration at the start of the experiment (time zero controls) and after 3 or 7 wk of incubation (aged controls: cosubstrate addition only, no white-rot fungus) The fungal growth substrates for fungal inoculum production were formulates F2 and F8 with C/N ratios of 200:1 and 51:1, respectively (Etheridge et al., 1998). F2 consisted of $750 \mathrm{~g} \mathrm{~kg}^{-1}$ pine sawdust, $167 \mathrm{~g} \mathrm{~kg}^{-1}$ deglutinated cornmeal, and $83 \mathrm{~g} \mathrm{~kg}^{-1}$ starch, and F8 of $563 \mathrm{~g} \mathrm{~kg}^{-1}$ pine sawdust, $387 \mathrm{~g} \mathrm{~kg}^{-1}$ kibbled rye, and $50 \mathrm{~g} \mathrm{~kg}^{-1}$ starch (Leštan et al., 1996; Walter et al., 2004, 2005a). These mixes were then hydrated to a moisture content of $560 \mathrm{~g} \mathrm{~kg}^{-1}$ before sterilization $\left(121^{\circ} \mathrm{C}, 20 \mathrm{~min}\right)$. The co-substrate amendment, F15, was composed of $330 \mathrm{~g} \mathrm{~kg}^{-1}$ Douglas fir sawdust and $110 \mathrm{~g} \mathrm{~kg}^{-1}$ corn grits (dry wt.) and $560 \mathrm{~g} \mathrm{~kg}^{-1}$ moisture. The sawdust and grain moisture content was determined $\left(60^{\circ} \mathrm{C}, 72 \mathrm{~h}\right)$. The fungal inoculum and co-substrate amendment were produced by the methods published previously (Ford et al., 2007).

\section{Experiments for Assessment of Bioaugmentation Parameters}

\section{Effect of SAFI Ratio}

This experiment was designed to determine the effect of five different ratios of substrate amendment to fungal inocula (SAFI ratio) on extracellular enzyme expression and PCP residue analysis after bioaugmentation. The PCP-soil mix consisted of $36.5 \mathrm{~g}$ of contaminated field soil, $247 \mathrm{~g}$ of clay loam and $60 \mathrm{~g}$ of water (4.00-mm sieve). One hundred and thirty five grams of SAFI was added to this mix and then distributed into three 280-mL (Ford et al., 2007) containers (157 $\mathrm{g}$ each) to produce the soil microcosms. This amount ( $135 \mathrm{~g}$ ) was used in subsequent experiments. The five different SAFI ratios, 85:15, 70:30, 50:50, 30:70, and 15:85 were used. Alternatively, using a unit-based expression, $1.000 \mathrm{~kg}$ of the 85:15 SAFI ratio consists of $850 \mathrm{~g}$ of co-substrate amendment (F15) and $150 \mathrm{~g}$ of fungal inocula (F8). The SAFI to PCP-soil ratio, by dry weight was 1:4 (Morgan et al., 1993). The dry weight of fungal inocula therefore varied from 31 to $175 \mathrm{~g} \mathrm{~kg}^{-1}$ PCPcontaminated soil. A total of 30 soil microcosms ( $157 \mathrm{~g}$ each) were produced for 10 treatments, hence three containers in triplicate for each isolate (2) at each SAFI ratio (5) were used. In addition, the SAFI ratios above ( $45 \mathrm{~g}$ total weight for each container) for both isolates were inoculated into $92 \mathrm{~g}$ of clay loam, with $21 \mathrm{~g}$ of water as a control, without the PCP-contaminated field soil. There was one container for each isolate at each SAFI ratio. The incubation temperature for this experiment and subsequent experiments was $23^{\circ} \mathrm{C} \pm 2^{\circ} \mathrm{C}$. Sampling for laccase activity was on Days 3, 6, 9, 12 , and 15 . Only the extracts on Days 12 and 15 were tested for $\mathrm{MnP}$ activity. The PCP-soil mixes inoculated with the 50:50, 30:70, and 15:85 SAFI ratios were stored at $-20^{\circ} \mathrm{C}$ after $3 \mathrm{wk}$ of incubation for chlorophenol residue analysis.

\section{Effect of PCP Concentration}

The aim of this experiment was to assess the effect of five different PCP concentrations in the PCP-soil mix (4.00-mm sieve) on white-rot fungal colonization and PCP biodegradation. The fungal growth substrate used was F8. The isolates were HR131 and HR577. The five combinations by weight for the aged PCP residue (6495 $\mathrm{mg} \mathrm{kg}^{-1} \mathrm{dry}$ wt.), clay loam, and water respectively, used to produce the PCP-soil mixes were 9.1, 266, and $67 \mathrm{~g}$; 18.2, 260, and $64 \mathrm{~g} ; 36.5,247$, and $60 \mathrm{~g} ; 73.0,220$, and $50 \mathrm{~g}$; and 109.5, 193, and $40 \mathrm{~g}$. These PCP-soil mixes were designed to give the following approximate PCP levels in the time zero and aged controls (Ford et al., 2007): 175, 375, 750, 1500, and $2250 \mathrm{mg} \mathrm{kg}^{-1}$, respectively (dry wt). The SAFI ratio was constant at 30:70. This gave 10 treatment combinations in triplicate, producing $30 \times 280 \mathrm{~mL}$, SAFI-inoculated PCP-soil mix containers at the five different PCP concentration levels for both white-rot fungi isolates. The sampling for laccase and $\mathrm{MnP}$ activity, and PCP biodegradation was as above; however, all repeated measures time points were sampled nondestructively for laccase and MnP.

\section{Biodegradation Time Course}

The aim of the biodegradation time course was to assess PCP disappearance over 7 wk for the two New Zealand Trametes isolates (HR131 \& HR577), and in addition, to correlate these with enzyme assay data, and to compare them with literature values (Walter et al., 2005a) for biodegradation rates of PCP. The fungal growth substrates were F2 and F8. This gave a $2^{2}$ factorial design with five repeated measures. The sampling times were 1 , $2,3,5$, and $7 \mathrm{wk}$. This destructive sampling regime resulted in the production of 60 containers, 20 lots of triplicate containers with $157 \mathrm{~g}$ of material (2.80-mm sieve) produced as above in each container. The SAFI ratio was 15:85, and the soil mixture consisted of $36.5 \mathrm{~g}$ contaminated soil, $247 \mathrm{~g}$ clay loam, and $60 \mathrm{~g}$ water giving a final PCP concentration of $1065 \mathrm{mg} \mathrm{kg}^{-1}$.

\section{Trametes spp. vs. Phanerochaete spp. for PCP Removal}

The aim was to inoculate the PCP-soil mix with P. chrysosporium (two isolates) and P. sordida grown on the Monterey pine kibbled rye-based formulate F8 to assess PCP degradation and PCA production, and to compare with the New Zealand Trametes isolates (HR131 and HR577), particularly T. versicolor. Three Phanerochaete isolates were grown on F8 under the conditions reported previously (Ford et al., 2007) for the New Zealand Trametes isolates T. versicolor HR131 and isolate HR577, then inoculated into the PCP-soil mix (2.80-mm sieve, final PCP concentration of $1065 \mathrm{mg} \mathrm{kg}^{-1}$ ) in triplicate as reported previously (Ford et al., 2007) with a SAFI ratio of 15:85. The co-substrate amendment was F15. After 7 wk of incubation at $23^{\circ} \mathrm{C}$, the $P h a-$ nerochaete isolate soil microcosms were fumigated using a sodium azide solution (Rost et al., 2002), before storage at $-20^{\circ} \mathrm{C}$.

\section{Chemical Residue Analysis and Extracellular Enzyme Measurement}

Most of the methodology was reported in a previous study (Ford et al., 2007). Briefly, laccase was measured by peroxide independent dimerization of 2,6 dimethoxyphenol ( $\lambda 465$ $\mathrm{nm})$; and manganese peroxidase activity by measurement of the formation of the Mn III malonate complex $(\lambda 270 \mathrm{~nm})$ spectrophotometrically. The sampling from the soil microcosm containers $(3-5 \mathrm{~g})$, with a $1.5 \mathrm{~cm}$ diam. cork borer, for extra cellular enzyme activity was performed in duplicate. 

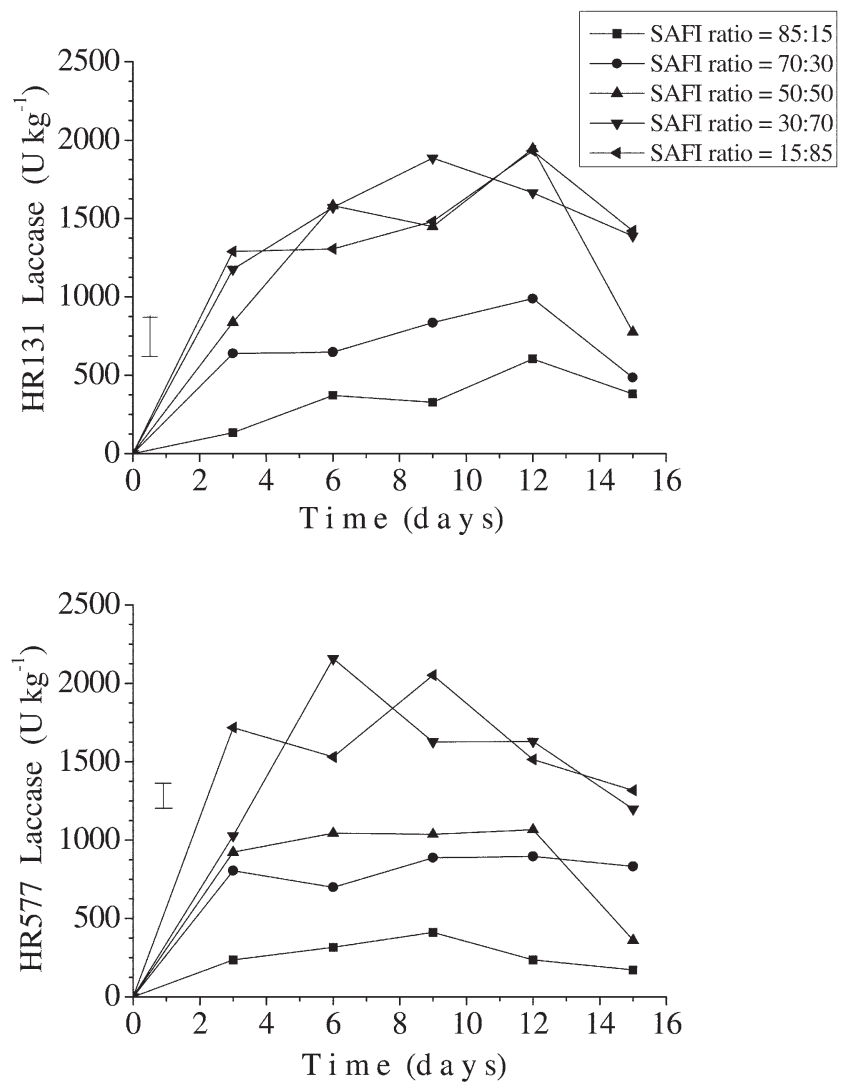

Fig. 1. Laccase activity for the New Zealand white-rot fungal isolates Trametes versicolor HR131 and Trametes spp. HR577 after bioaugmentation into a $697 \mathrm{mg} \mathrm{kg}^{-1}$ pentachlorophenolcontaminated field soil at different SAFI ratios (substrate amendment to fungal inoculum ratio). Error bar $=$ the $5 \%$ least LSD on the standard error of difference in the means. Pooled 95\% error bounds for the ANOVA repeated measures factor means $\left(\mathrm{U} \mathrm{kg}^{-1}\right)$ : SAFI ratio main effect \pm 112 , time and isolate, and SAFI ratio and isolate effects \pm 154 , and \pm 159 , respectively.

These subsamples were then extracted with $\mathrm{pH} 4.5$ malonate $(1 \mathrm{~h})$ and filtered with Whatman's No 5 filter paper. Pentachlorophenol and lower substituted chlorophenol residue

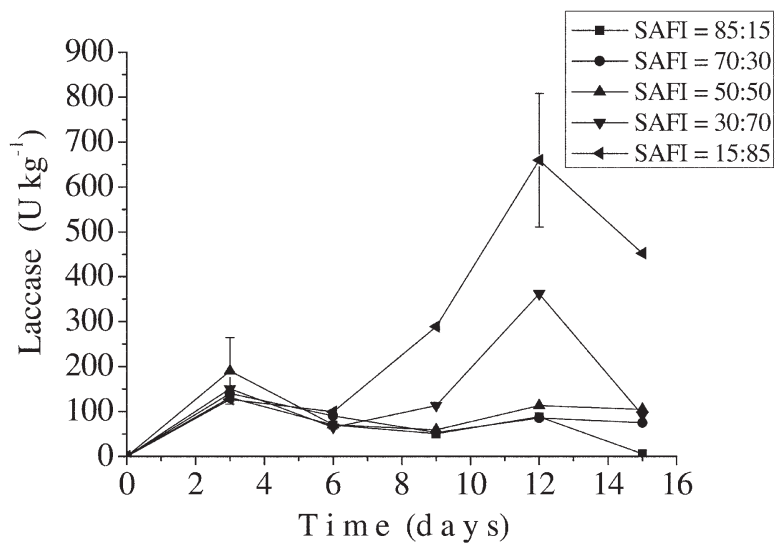

Fig. 2. Laccase activity for the New Zealand white-rot fungal isolates Trametes versicolor HR131 and Trametes spp. HR577 after bioaugmentation into a clay loam soil at different SAFI ratios (substrate amendment to fungal inoculum ratio); error bars represent the $95 \%$ confidence intervals.
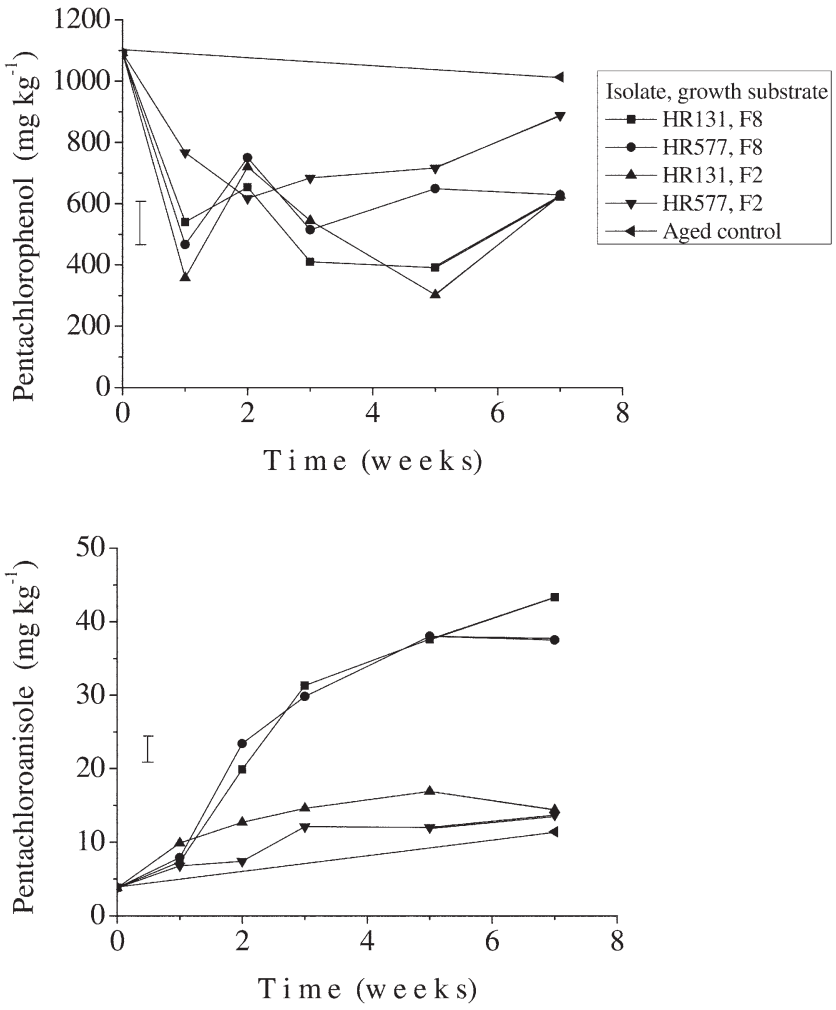

Fig. 3. Pentachlorophenol (PCP) removal and pentachloroanisole accumulation (PCA) over $7 \mathrm{wk}$ by the white-rot fungal isolates Trametes versicolor HR131 and Trametes sp. HR577 grown on high and (F8) low nitrogen growth (F2) substrates (C/N = 51 and 200) and inoculated into a $1065 \mathrm{mg} \mathrm{kg}^{-1}$ pentachlorophenolcontaminated field soil. Pooled $90 \%$ confidence intervals ( 7 wk, $\mathrm{mg} \mathrm{kg}^{-1}$ dry wt.): 268-982 (PCP, F8), and 510-952 (PCP, F2); 36-45 (PCA, F8), and 10-18 (PCA, F2); 344-662 (PCP, F8, 1-wk).

analysis were performed by acetone-hexane extraction from the aged field soil in acidic $(\mathrm{pH}<1.0)$ conditions (phosphoric acid). The chlorophenols and standards were derivatized with acetic anhydride before analysis by gas chromatography with electron capture detection (ECD) as reported in a previous study, or mass spectrometry (MS). Anisole standards were produced from a chlorophenol mix containing PCP; the three tetra chlorophenol isomers and four trichlorophenol isomers were derivatized with diazomethane and were analyzed by GC with either ECD (Ford et al., 2007) or MS as the detector, depending on availability of equipment and the detection level required. All values were expressed on a dried weight basis $\left(60^{\circ} \mathrm{C}, 3 \mathrm{~d}\right)$. Finally, all white-rot fungi soil microcosm cultures and controls for the factorial and non-factorial and subsequent experiments were stored at $-20^{\circ} \mathrm{C}$ after 1 to $7 \mathrm{wk}$ of incubation, respectively, and analyzed for PCP, PCA, and lower substituted chlorophenol biodegradation at a later date.

\section{Data Analysis}

The statistical analysis was a two-way ANOVA (Genstat 7.2; Payne et al., 2004) with five repeated measures for the results in Fig. 1, 2, 3, 4, 5, and 6, and an ANOVA for Fig. 7 and 8 results. Statistical significance from the two-way ANOVA results was expressed as the least significant dif- 

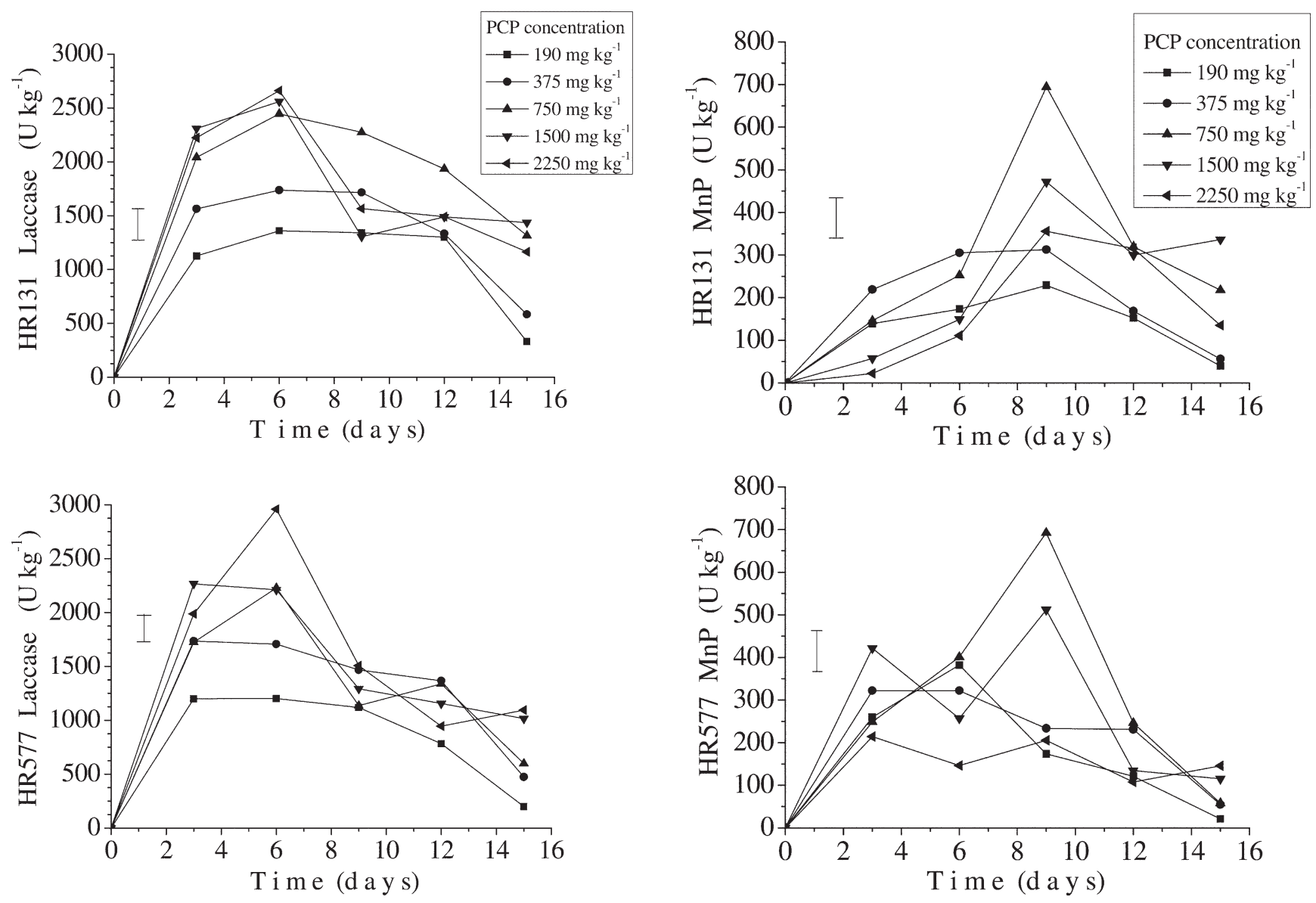

Fig. 4. Laccase activity for the New Zealand white-rot fungal isolates Trametes versicolor HR131 and Trametes spp. HR577 after bioaugmentation into various clay loam-pentachlorophenol (PCP)-contaminated soil mixtures. Pooled $95 \%$ error bounds for the factor means $\left(\mathrm{U} \mathrm{kg}^{-1}\right)$ : PCP concentration and isolate main effects \pm 203 , and \pm 128 , respectively, time and PCP concentration effect \pm 296 .

ference calculated from the standard error of difference in means; the ANOVA results were expressed as Fisher's least significant difference. In addition, all repeated-measures data were analyzed by REML (Restricted Maximum Likelihood), utilizing Genstat 7.2 (Brown and Kempton, 1994; Payne et al., 2004). The nonlinear REML analysis was performed with a first order autoregressive covariance structure (Payne et al., 2004), with the exception of the results from Fig. 6 (power covariance structure). Four outliers were eliminated from the biodegradation time course (Fig. 3) and there was one missing datum point. The four outliers were greater than the starting PCP concentration (1065 $\left.\mathrm{mg} \mathrm{kg}^{-1} \mathrm{PCP}\right)$. A missing-values algorithm (Payne et al., 2004) was used to retain orthogonality of the repeated-measures data. The outliers eliminated in the PCP biodegradation time course (Fig. 3) were from the week 2 and 7 time points. The outlying data points for week 2 were for the two Trametes isolates grown on the F8 formulate before bioaugmentation into the PCP-soil mix (Discussion). The week 7 data points were for isolate HR577 grown with F8 and F2, respectively, before inoculation.

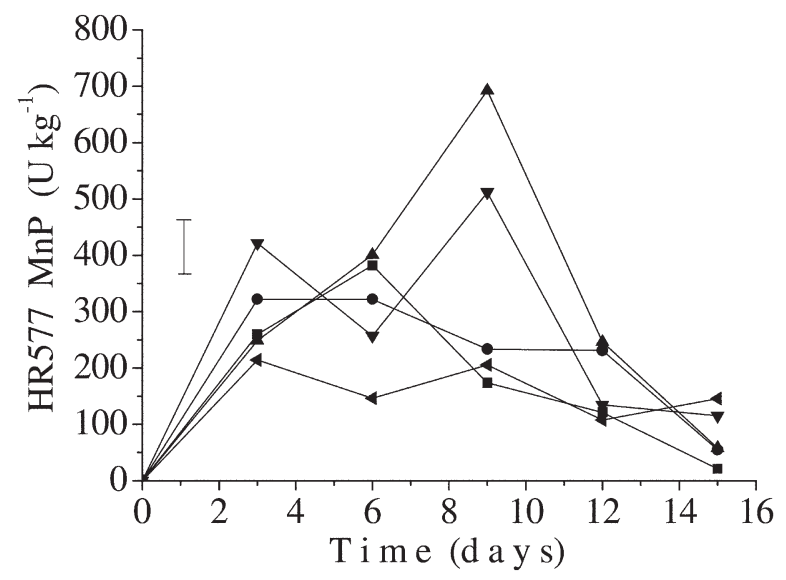

Fig. 5. Manganese peroxidase activity response for the New Zealand white-rot fungal isolates Trametes versicolor HR131 and Trametes spp. HR577 after bioaugmentation into various clay loam-pentachlorophenol (PCP)-contaminated soil mixtures. Pooled $95 \%$ error bounds for the factor means $\left(\mathrm{U} \mathrm{kg}^{-1}\right)$ : PCP concentration main effect \pm 66 , time and isolate, and time and PCP concentration effects \pm 75 , and 118 , respectively.

\section{Results}

\section{Soils}

The PCP-soil mix was produced in duplicate $(2.80-\mathrm{mm}$ sieve) and after co-substrate addition (time zero controls); the combined mean value was a PCP concentration of 1065 $\pm 160 \mathrm{mg} \mathrm{kg}^{-1}(n=9, \alpha=0.025)$. The 7 -wk aged controls had a PCP concentration of $1013 \pm 107 \mathrm{mg} \mathrm{kg}^{-1}(n=8$, $\alpha=0.025)$. The chlorophenol, fuel oil, and metal levels in the aged PCP residue soil sieved with the 2.80 and $4.00-\mathrm{mm}$ sieves are reported elsewhere (Ford et al., 2007). The PCP concentrations in the five PCP-soil-co-substrate amendment mixes (time zero controls) sieved with a 4.00 -mm sieve were $100 \pm 40(n=3), 452 \pm 720(n=3), 697 \pm 283(n=5), 1675$ $\pm 870(n=3)$, and $2137 \pm 1168 \mathrm{mg} \mathrm{kg}^{-1}(n=3) \mathrm{PCP}$ on a dry weight basis, respectively. The 7 -wk aged control values were 110,265 , and $653 \mathrm{mg} \mathrm{kg}^{-1}$ for the three lowest concentrations, respectively. There were no aged 7 -wk controls for the two highest PCP concentration treatments. 

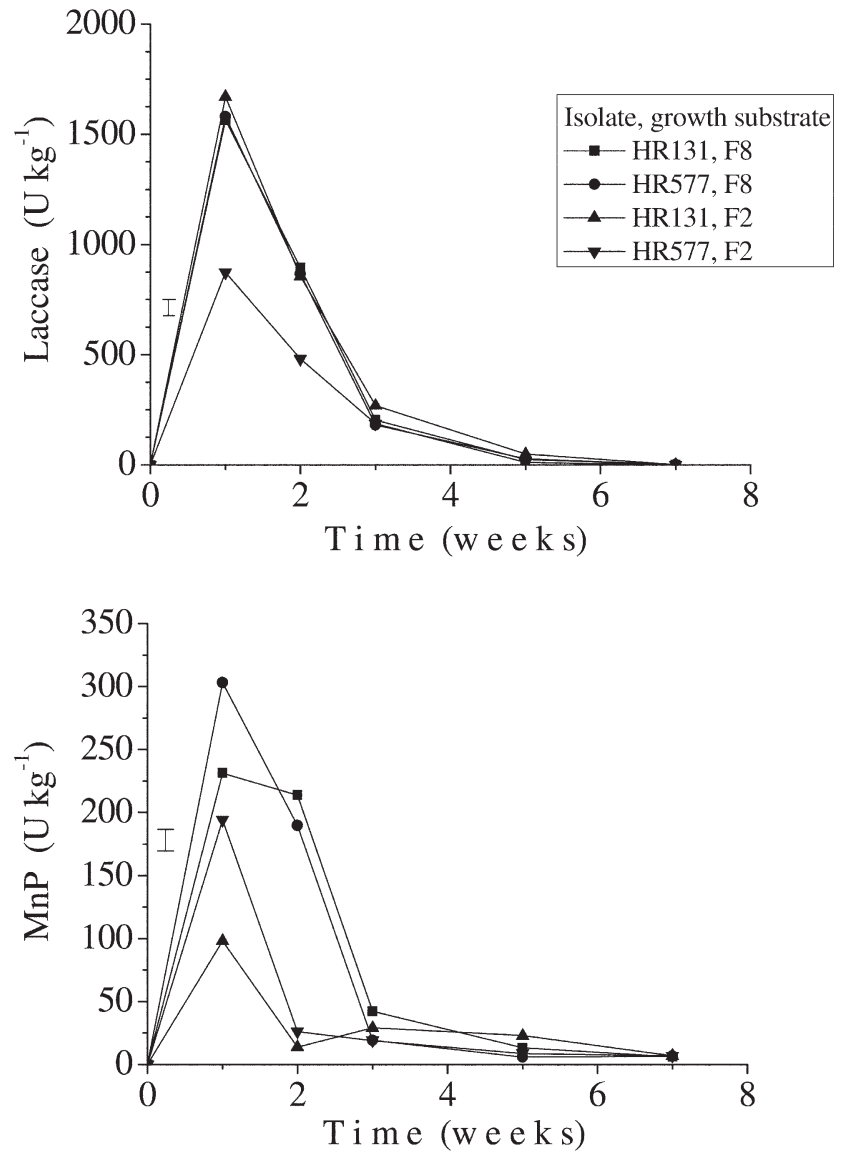

Fig. 6. Laccase and manganese peroxidase (MnP) activity for isolates T. versicolor HR131 and Trametes sp. HR577 grown on high and low nitrogen growth substrates ( $C / N=51: 1$ and 200:1) and inoculated into a $1065 \mathrm{mg} \mathrm{kg}^{-1}$ pentachlorophenolcontaminated field soil. Standard errors of differences (95\%) for factor means $\left(\mathrm{U} \mathrm{kg}^{-1}\right)$ : MnP formulate main effect, time and isolate effect, time and formulate effect $\pm 7, \pm 15$, and \pm 15 , respectively; laccase formulate and isolate main effects \pm 29 , time and isolate, and time and formulate effects \pm 56 , formulate and isolate effect \pm 41 .

\section{Effect of SAFI Ratio and PCP Concentration}

There was no difference between the white-rot fungi isolates HR131 and HR577 in laccase response $(P>0.1)$ for the different SAFI ratio treatments (Fig. 1). However, there was a significant isolate interaction with time $(P=0.017)$; the laccase activity for isolate HR577 obviously peaked earlier than T. versicolor HR131. There were significant differences $(P<0.001)$ among the SAFI ratios (Fig. 1). These were less pronounced for the three SAFI ratios with the most fungal inoculum, 50:50, 30:70, and 15:85. However, there was a significant interaction between isolate type and SAFI ratio $(P=0.032)$, because there was considerably lower laccase activity for isolate HR577 in the 50:50 SAFI ratio inoculation compared with T. versicolor $(P<0.05)$. The highest fungal inocula loading, the 15:85 SAFI ratio, was quickest at colonizing the PCP-soil mix after $3 \mathrm{~d}(P<0.05)$; this was more pronounced for isolate HR577 than for T. versicolor HR131. The laccase activity in both isolates had peaked and was declining at $15 \mathrm{~d}$ (Fig. 1). The laccase activity produced by the 50:50 SAFI ratio treatments

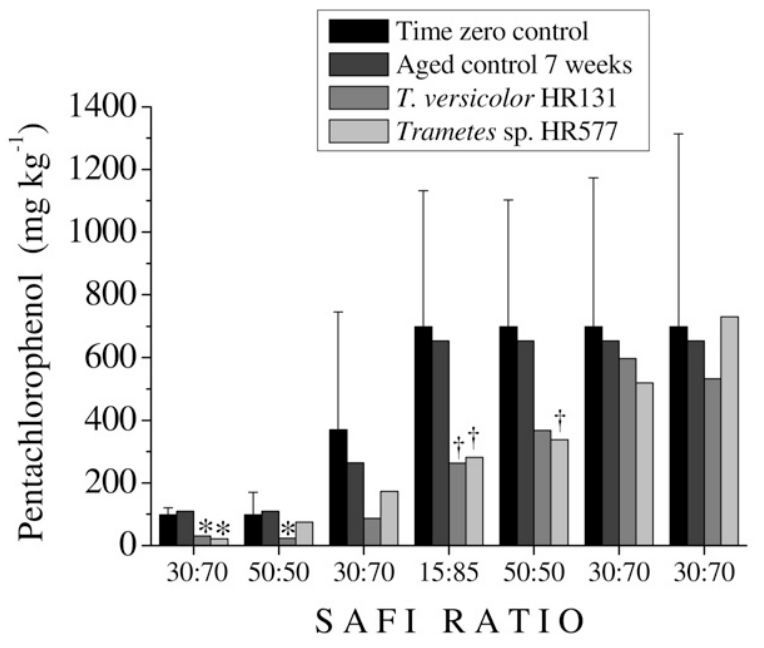

Fig. 7. Pentachlorophenol removal over 3 wk by the white-rot fungal isolates Trametes versicolor HR131 and Trametes sp. HR577 after bioaugmentation at different SAFI ratios (cosubstrate amendment and fungal inocula ratio) into three pentachlorophenol-contaminated field soils. The error bars represent Fisher's least significant difference, ${ }^{*}=$ significance at the $5 \%$ level, $\uparrow=$ significance at the $10 \%$ level.

for both isolates after bioaugmentation was no different from when this treatment was used in a previous study (Ford et al., 2007).

In contrast, in the controls without PCP (Fig. 2) only the two SAFI ratios with the highest fungal inoculum loading (15:85 and 30:70) promoted a significant laccase response. The laccase peak was significantly $(P<0.05)$ lower and later $(12 \mathrm{~d})$ than was observed in the aged PCP residue-supplemented clay loam (Fig. 1). The grand laccase means and 95\% confidence intervals for the control white-rot fungal cultures without PCP-contaminated soil addition and the PCP-soil mix cultures were $150 \pm 70 \mathrm{U} \mathrm{kg}^{-1}$ and $1090 \pm 100 \mathrm{U} \mathrm{kg}^{-1}$, respectively. Therefore, the PCP-soil mix induced laccase. There was considerable colonization of the control soil (zero PCP) by the fungi at the two highest fungal inoculum loadings by both isolates after $16 \mathrm{~h}$. There was no laccase or $\mathrm{MnP}$ activity detected in the 7-wk aged controls with no white-rot fungi addition.

There was evidence of an isolate difference for $\mathrm{MnP}$ expression $(P=0.050)$, with $T$. versicolor HR131 expressing more $\mathrm{MnP}$ than isolate HR577, and a fungal inocula loading difference $(P<0.001)$. The grand $\mathrm{MnP}$ mean was $271 \pm 54 \mathrm{U} \mathrm{kg}^{-1}$. The MnP control readings (no PCP-contaminated field soil, grand $\mathrm{MnP}$ mean $\left.=105 \pm 54 \mathrm{U} \mathrm{kg}^{-1}\right)$ were somewhat lower than reported elsewhere (Boyle, 1994). The PCP residue analysis results are presented in Fig. 7.

Increasing the $\mathrm{PCP}$ concentration by adding a greater proportion of PCP-contaminated soil (Fig. 4) in the PCP-soil mixes produced a significant increase in laccase expression $(P<0.001)$; there was a significant laccase response difference for the two isolates $(P=0.011)$ because $T$. versicolor HR131 expressed more laccase than isolate HR577 (Fig. 4). There was a sharp decrease in laccase activity after $6 \mathrm{~d}$ for the two highest PCP concentration treatments for T. versicolor HR131 (Fig. 4). Furthermore, there was an equivalent decrease in laccase activity for isolate HR577 in the $697 \mathrm{mg} \mathrm{kg}^{-1} \mathrm{PCP}-$ soil mix after $6 \mathrm{~d}$, as well as for the two 
higher PCP treatment levels (Fig. 4). Accordingly, the time and PCP interaction $(P<0.001)$ for laccase response was also significant. The visual colonization levels (mycelial appearance) were highest for the two lowest PCP concentration treatment levels and there was little evidence of mycelia present in the two higher treatment levels for the T. versicolor HR131 isolate.

The main factors, time and PCP concentration of the soil mix $(P<0.001$ and $P=0.003$, respectively), had a significant effect on $\mathrm{MnP}$ expression (Fig. 5). The peak MnP expression was for the $697 \mathrm{mg} \mathrm{kg}^{-1}$ PCP treatment; subsequently, as the PCP concentration of the PCP-soil mix increased, $\mathrm{MnP}$ activity dropped considerably. There was a significant interaction between PCP concentration and time $(P=0.002)$ as $\mathrm{MnP}$ expression peaked after $9 \mathrm{~d}$. The overall means of both isolates demonstrated no significant isolate differences $(P>0.1)$. However, a significant time and isolate effect $(P=0.007)$ was apparent, as isolate HR577 expressed higher levels of $\mathrm{MnP}$ than T. versicolor earlier in the time course $(3 \& 6 \mathrm{~d})$. The PCP residue analysis results are presented in Fig. 7.

\section{Effect of Different Inoculation Techniques on Residue Analysis} $P C P$

There was significant PCP reduction by at least one white-rot fungal isolate in four out of seven treatments $(P<0.1)$. Alternatively, only one out of five, for the 30:70 SAFI ratio treatments, at the five different PCP concentrations, was significant for PCP removal. Pentachlorophenol removal varied from 40 to $80 \%$ across all treatments that were significant for PCP reduction (Fig. 7). The results for the higher PCP concentration treatments (1675 and $2137 \mathrm{mg}$ $\mathrm{kg}^{-1}$ ) showed 46 and 37\% reduction of PCP by isolate HR577, but these results were statistically insignificant $(P>0.1)$. There was an increase in $\mathrm{pH}$ over the time course of the experiments for all treatments apart from the 7-wk aged control without any white-rot fungal addition (no $\mathrm{pH}$ change) and the controls without PCPcontaminated soil addition (a pH decrease). The magnitude of the $\mathrm{pH}$ increase changed with SAFI ratio and the concentration of the PCP-contaminated field soil in the PCP-soil mix.

\section{Other Chlorophenols and Anisoles}

All treatments (apart from the two 30:70, $697 \mathrm{mg} \mathrm{kg}^{-1} \mathrm{PCP}$ treatments in Fig. 7) demonstrated significant 2,3,4,6-tetrachlorophenol reduction $(P<0.1)$, but there was no statistical evidence that it was entirely fungal promoted, as significant reductions were also noted in the 7 -wk aged controls. Trichlorophenol anisole derivatives were detected (2,4,6 and 2,3,4 isomers, $\sim 30$ $\left.\mu \mathrm{g} \mathrm{kg}^{-1}\right)$ in two treatments (15:85 SAFI ratio treatment and one $697 \mathrm{mg} \mathrm{kg}^{-1}$ PCP, 30:70 SAFI ratio treatment, Fig. 7) and two aged controls (175 and $375 \mathrm{mg} \mathrm{kg}^{-1}$ treatments, Fig. 7). There was no PCA production greater than $5 \%$ of the original PCP concentration in any treatments and statistically, there were no significant differences between isolates in Fig. 7.

\section{Biodegradation Time Course}

Figure 6 shows that the two New Zealand Trametes isolates, when grown on the F8 growth substrate before bioaugmentation, promoted higher laccase and $\mathrm{MnP}$ activity overall than when grown on the $\mathrm{F} 2$ growth substrate $(P<0.001)$. All the main effects and their two factor interactions had a significant effect for laccase expression $(P<0.001)$. In contrast, for the $\mathrm{MnP}$ expression, there was no significant difference between the two isolate types. However, both the time and formulate main effects had a significant effect on $\mathrm{MnP}$ expression $(P<0.001)$; the two factor interactions for time and formulate, time and isolate, were also significant $(P<$ 0.001). The MnP activity peak was lower than noted for previous work (Ford et al., 2007) (note the change of scale) and probably peaked between weeks 1 and 2 . The formulate difference observed for laccase activity was due to the low mean laccase reading in the inoculated PCP-soil mix for isolate HR577 grown on the F2 growth substrate (Fig. 6). There was more visual colonization on the surface of the PCP-soil mix by both T. versicolor and isolate HR577 when grown on the F8 growth substrate, than when they were grown and inoculated on the F2 growth substrate. Non white-rot fungal species were observed colonizing all the PCP-soil mixes within $9 \mathrm{~d}$ after bioaugmentation, but not in the aged controls, as in previous work (Ford et al., 2007).

In addition, the $\mathrm{pH}$ of the $\mathrm{PCP}-$-soil mixes after bioaugmentation changed. This change was dependant on growth substrate formulation. Both Trametes isolates, when grown on the F8 growth substrate, increased the $\mathrm{pH}$ of the PCP-soil mix from 5.5 to 7.6 after $1 \mathrm{wk}$. This effect was not observed when the fungi were grown on the F2 growth substrate, since there was no detectable $\mathrm{pH}$ change when isolate HR577 was inoculated ( $\mathrm{pH}$ 5.6), and the $\mathrm{pH}$ of the $\mathrm{PCP}-$ soil mix fell to $\mathrm{pH} 5.0$ when isolate HR131 was inoculated. There are no reports in the literature of a pH rise in aged $\mathrm{PCP}$ residue contaminated field soils after bioaugmentation of white-rot fungi. The $\mathrm{pH}$ of the F8 fungal inoculum before inoculation was 5.3.

The time factor for the biodegradation of PCP over time course (Fig. 3) was not significant $(P>0.1)$ when analyzed by 
repeated measures factorial analysis. This suggests most of the observed PCP biodegradation or disappearance (Roy-Arcand and Archibald, 1991) probably occurred within the first week. Both New Zealand Trametes isolates, when grown on the F8 growth substrate, removed more PCP overall from the PCPsoil mix than when grown on the F2 growth substrate before bioaugmentation $(P=0.035)$. T. versicolor $\mathrm{HR} 131$ removed more PCP than isolate HR577 $(P=0.001)$ from this PCPsoil mix $\left(1065 \mathrm{mg} \mathrm{kg}^{-1}\right)$. The two factor interaction between isolate and formulate was also significant $(P=0.016)$. This is a result of $T$. versicolor HR131 removing more PCP than isolate HR577, when the F2 growth substrate was used (Fig. 3).

The PCA increase (Fig. 3) over the 7 -wk time course from both fungal growth substrates was significant $(P<0.001)$. The growth substrate difference for PCA production was also significant $(P<0.001)$, with more PCA being produced by the lower $\mathrm{C} / \mathrm{N}$ ratio formulate (F8) than by the cornmeal starch formulate (F2). There was also a small significant difference between the isolates for PCA production $(P=0.092)$ because T. versicolor HR131 produced more PCA than Trametes sp. isolate HR577. However, this is probably a consequence of $T$. versicolor removing more PCP overall.

The PCP biodegradation rate in the 7 -wk aged controls was $1.1 \pm 5.2 \mathrm{mg} \mathrm{kg}^{-1} \mathrm{~d}^{-1},(\alpha=0.025, n=8)$ on a dry weight basis. This rate is similar to a killed control biodegradation rate reported in another study $\left(5.4 \mathrm{mg} \mathrm{kg}^{-1} \mathrm{~d}^{-1}\right.$, standard error $=0.74$ ) (Walter et al., 2005a), with a similar PCP-soil mix. Therefore, this result was no different from a zero PCP biodegradation rate. The PCP biodegradation rate calculated in the first $7 \mathrm{~d}$ of the time course (Fig. 3) by combining the results from both Trametes isolates was $80 \pm 50 \mathrm{mg} \mathrm{kg}^{-1} \mathrm{~d}^{-1}$ $(\alpha=0.025, n=6)$. This result is significantly higher than other literature values reported for PCP biodegradation rates (Laine and Jorgensen, 1997) in PCP-contaminated soil. However, only two time points were used to calculate this rate and the aged nature of the contaminated soil probably contributed to the significant variation; therefore, it should be regarded only as an approximate value.

\section{Phanerochaete spp. vs. Trametes spp.}

The three Phanerochaete isolates reported in Fig. 8 produced, on average, PCP removal similar to the New Zealand Trametes isolates when grown on the F8 growth substrate, for bioaugmentation into the PCP-soil mix. Overall removal of PCP was 40 to $65 \%$. However, there was considerable variation among individual replicates, since there was up to $95 \%$ reduction (P. sordida) of PCP in some of the samples analyzed, and this resulted in a somewhat inflated LSD value (Fig. 8). However, as for Fig. 3, there was less variation in PCA produced. Phanerochaete sordida removed the most PCP (65\%) of all the white-rot fungi and produced the highest amount of PCA (Fig. 8). The majority of PCP removed was converted to PCA by the three Phanerochaete isolates. Phanerochaete sordida was the only white-rot fungus that completely colonized the $1065 \mathrm{mg} \mathrm{kg}^{-1}$ PCP-soil mix in the entire study.

\section{Discussion}

\section{Effect of SAFI Ratio and PCP Concentration}

The laccase activity in the "PCP-soil mix" may have been induced by the fuel oil co-contaminant or by copper (Gianfreda et al., 1999), as well as by PCP. Copper is a laccase co-factor, and preliminary experiments (data not shown) demonstrated that diesel fuel when added to the growth substrate induced laccase activity. The rise in soil $\mathrm{pH}$ values above 7.0 for the SAFI ratios 30:70 and 15:85 after 3 wk could also have contributed to the insignificant differences measured for laccase activity (Fig. 1) for the three SAFI ratios 50:50, 30:70, and 15:85, since $\mathrm{pH}$ values above 7.0 inhibit laccase activity (Gianfreda et al., 1999).

The toxicity of PCP to the fungus appears to have inhibited significant biodegradation at 1675 and $2137 \mathrm{mg} \mathrm{kg}^{-1}$ PCP, since the PCP removal was statistically insignificant (Walter et al., 2005a). However, the variability in some of the results was significant (Fig. 7). Therefore, the PCP-contaminated field soil and the clay loam were passed through the smaller sieve size $(2.80 \mathrm{~mm})$ for all subsequent experiments to reduce the variation in the results. The insignificant PCP reduction in both the 30:70 SAFI ratio treatments when inoculated into the PCP-soil mix (697 $\mathrm{mg} \mathrm{kg}^{-1}$ PCP concentration, Fig. 7) was a surprise, because this treatment had given the highest levels of $\mathrm{MnP}$ production (Fig. 5) for both isolates in this series of experiments. A possible explanation for this phenomenon is discussed below.

\section{Biodegradation Time Course}

The aged nature of the PCP-contaminated field soil suggests the possibility that a reasonable portion of the PCP was still sequestered to the point of not being extractable by the methodology that was used (Alexander, 1999; Northcott and Jones, 2000). The extraction efficiency of PCP from the spiked soil samples in a substrate amendment-clay loam mix was $99.4 \%$ of that extracted from a spiked solvent blank without any soil. This problem has been reported before with the same soil (Walter et al., 2005a). However, PCP in a PCP-soil mix $\left(800 \mathrm{mg} \mathrm{kg}^{-1}\right)$, the same as used in this study, was reduced to $4 \mathrm{mg} \mathrm{kg}^{-1}$ over $2 \mathrm{yr}$ (Walter et al., 2005b). This could not occur without some release of highly sequestered PCP, even though it was a slow process.

There was a significant increase in the PCP levels in three of the four formulate isolate combinations from week 1 to 2 after inoculation in the biodegradation time course, even with the outliers eliminated from week 2 . This may possibly be the result first of random variation, which is unlikely since the PCP disappearance in the first week is correlated with the laccase activity in Fig. 6. The only treatment that did not show this trend had the lowest laccase activity after $1 \mathrm{wk}$ and the lowest PCP reduction (Fig. 3 and 6). Some potential mechanisms for this phenomenon are discussed below.

First, the initial rapid disappearance of bioavailable PCP may have resulted in diffusion of PCP out of micropores and nanopores present in the soil mix components. Second, there was an increase in $\mathrm{pH}$ from 5.5 to 7.6 in two treatments after week 1 with the outliers eliminated (see data analysis), and since PCP is 
generally sequestered in soil at low pH (Divincenzo and Sparks, 1997, 2001), this probably aided the release of sequestered PCP for extraction. There was no $\mathrm{pH}$ change in the aged controls with no white-rot fungi and the bioaugmentation treatment with the lowest extracellular enzyme activity. This suggests the PCP increase in the three treatments from week 1 to 2 (Fig. 3) were white-rot fungal promoted. This increase in $\mathrm{pH}$ after bioaugmentation was not expected, since the production of organic acids by the fungi usually results in a pH fall (Leštan et al., 1996; Walter et al., 2004, 2005a), which was observed in the control treatments without any PCP-contaminated field soil addition (Fig. 2.).

Third, bound PCP residues, for instance bound by hydrogen bonding or complexed with clay or soil organic matter (Alexander, 1999), have undergone a reaction catalyzed by the white-rot fungal extracellular enzymes or some other biotic or abiotic mechanism, and been extracted as PCP (Northcott and Jones, 2000). Therefore, the PCP rise in the treatments with the outliers eliminated in the data analysis was probably a combination of both the $\mathrm{pH}$ rise promoted by the fungi, and the diffusion mechanism promoted by the PCP concentration gradient change mentioned previously. The latter mechanism was probably the main mechanism that promoted the PCP concentration rise after week 1 when the fungal inoculum was the isolate HR131-F2 formulation. The effect of the third mechanism is unknown.

These mechanisms may also explain the duplicate 30:70 SAFI ratio treatments producing insignificant $\mathrm{PCP}$ removal despite having significantly higher $\mathrm{MnP}$ activity levels $(P<0.05)$ in the contaminated soil (Fig. 5 and 7 ) than the 50:50 SAFI ratio treatments. Figure 3 shows a decrease in PCP levels after week 2 in three whiterot fungal treatments (15:85 SAFI ratio) that showed an increase after week 1 . Therefore, possibly the extra fungal loading in this treatment aided further PCP reduction after week 2 of the time course, while the lesser fungal loading in the 30:70 ratio treatment did not. In addition, the malonate extracts for $\mathrm{MnP}$ and laccase activity for the 30:70 and 15:85 SAFI ratio treatments were the only extracts highly colored (a dark "tan" color). Therefore, possibly the 50:50 SAFI ratio treatments degraded only a limited amount of PCP that was bioavailable in the PCP-soil mix, and there was a large portion still sequestered and not extracted. The $\mathrm{pH}$ of the PCP-soil mixes inoculated with this SAFI ratio was 7.2 on average, lower than the 30:70 and 15:85 SAFI ratio values (7.5 and 7.6, respectively), which also supports this argument.

Drying of the PCP-contaminated field soil for moisture analysis revealed dark brown particles that produced considerable amounts of color when added to dichloromethane or hexane. The tan color observed in some of the malonate extracts discussed previously could be caused by the $\mathrm{pH}$ increase to 7.5 or by some other fungalmediated process dissolving or partially dissolving this material. These particles could be glassified droplets (Nadebaum et al., 1992; Luthy et al., 1997) of the original PCP fuel oil formulation and could be the factor promoting the variability of the results through PCP extraction percentages changing in the bioaugmentation treatments over time (Fig. 3 and 8), as discussed previously. These particles were easily identified; therefore, their removal may allow significantly better fungal colonization and PCP reduction in future studies using this contaminated field soil. Finally, the Microtox bioassay demonstrated toxicity reduction that was statistically significant for the T. versicolor HR131 (F8 growth substrate) inoculated cultures after 7 wk (data not shown).

The PCA increase observed in Fig. 3 after week 1 may be due to the colonization of non white-rot fungi that was observed $9 \mathrm{~d}$ after bioaugmentation, and an increase in biological activity of the native soil microflora. Increased PCA activity has been detected in PCP-spiked soils with mixed microflora in a past study following bioaugmentation of Lentinula edodes (Okeke et al., 1997). The lowest PCA level detected after $7 \mathrm{wk}$ was in the aged controls (trend), which in combination with the PCP concentration $\left(1013 \mathrm{mg} \mathrm{kg}^{-1}\right)$ in the aged controls (co-substrate present, but no white-rot fungus) suggests minimal PCP biodegradation throughout the time course in these samples (Fig. 3).

\section{Comparison between Trametes spp. and Phanerochaete spp. for PCP Removal}

The removal of PCP with the subsequent accumulation of PCA for all the Phanerochaete isolates (Fig. 8) were as expected (Lamar et al., 1990; Lamar and Dietrich, 1990a; Walter et al., 2004). However, since the culture conditions that promote PCA production are not necessarily dependent on nitrogen-limiting or nitrogen-sufficient conditions (Lamar and Dietrich, 1990a; Lamar et al., 1990; Leštan et al., 1996), it was not anticipated that close to $100 \%$ of the PCP removed would be methylated to PCA with the C/N ratio of the formulate being 51:1. Alternatively, possibly the Phanerochaete spp. isolates have also increased the bioavailability of the PCP sequestered in the fuel oil, not only for biodegradation, but also for subsequent extraction of more PCP by acetone-hexane. A similar $\mathrm{pH}$ increase to 7.6 was observed, as was reported above, for the New Zealand Trametes isolates. This would also explain the results in Fig. 8, since 100\% of PCP conversion to PCA is unlikely; past studies have reported at least some mineralization or polymerization of PCP as well as methylation (Lamar et al., 1990; Leštan et al., 1996; Rüttimann-Johnson and Lamar, 1996).

\section{Conclusions}

There was evidence that the majority of PCP in a $1065 \mathrm{mg} \mathrm{kg}^{-1}$ PCP-contaminated field soil (a maximum of 66\%) was removed by Trametes versicolor isolate HR131 and Trametes sp. isolate HR577 in the first week after bioaugmentation. The removal rate was $80 \pm 50 \mathrm{mg} \mathrm{kg}^{-1} \mathrm{~d}^{-1}$ (dry wt.), $\alpha=$ 0.025 . The aged nature and physical properties of the PCP-contaminated field soil, the extraction methodology, and chemical changes promoted by the white-rot fungi ( $\mathrm{pH}$ increase) probably resulted in more PCP being extracted from the contaminated soil after the first week following bioaugmentation. This resulted in an apparent drop in the amount of PCP removed. The underlying mechanism that promoted the $\mathrm{pH}$ rise is unknown. The maximum PCP removed after $7 \mathrm{wk}$ from this $1065 \mathrm{mg}$ $\mathrm{kg}^{-1}$ PCP-contaminated soil was $65 \%$ by Phanerochaete sordida ATCC 90628. There was limited PCA (2-9\%) production from the degraded PCP by the New Zealand white-rot fungi and this production was growth substrate dependant. The majority of the PCP degraded was converted to PCA by the three Phanerochaete 
spp. isolates. There was no significant PCP removal in contaminated field soils above a PCP concentration of $1065 \mathrm{mg} \mathrm{kg}^{-1}$. The recommendations for future study include the mechanisms underlying the changes the white-rot fungi promote in PCP bioavailability and extractability in the contaminated field soil, and the removal of glassified droplets of what was considered the original PCP in fuel oil formulation, to enhance fungal colonization and PCP removal from the contaminated field soil. Fungal formulation and bioaugmentation processes have been optimized to facilitate white rot fungal survival and degradation of PCP in highly contaminated field soils above $1800 \mathrm{mg} \mathrm{kg}^{-1}$ PCP concentration.

\section{Acknowledgments}

This research was funded by the New Zealand Foundation for Research, Science, and Technology, Tredi New Zealand Ltd and The Horticulture and Food Research Inst. of New Zealand Ltd (HortResearch) via a Technology New Zealand Enterprise Scholarship (Contract No LINX03008).

\section{References}

Alexander, M. 1999. Bioavailability: Aging, sequestering, and complexing. p. 157167. Biodegradation and bioremediation, 2nd ed. Academic Press, Ithaca.

Aust, S.D., P.R. Swaner, and J.D. Stahl. 2004. Detoxification and metabolism of chemicals by white-rot fungi. Pesticide decontamination and detoxification. ACS Symp. Ser. 863:3-14.

Boyle, D.C. 1994. Development of a practical method for inducing white rot fungi to grow into and degrade organopollutants in soil. Can. J. Microbiol. 41:345-353.

Brown, H.K., and R.A. Kempton. 1994. The application of reml in clinical trials. Stat. Med. 13:1601-1617.

Bumpus, J.A., and S.D. Aust. 1985. Biodegradation of environmental pollutants by the white rot fungus Phanerochaete chrysosporium: Involvement of the lignin degrading system. Bioessays 6:166-170.

Divincenzo, J.P., and D.L. Sparks. 1997. Slow sorption kinetics of pentachlorophenol on soil: Concentration effects. Environ. Sci. Technol. 31:977-983.

Divincenzo, J.P., and D.L. Sparks. 2001. Sorption of the neutral and charged forms of pentachlorophenol on soil: Evidence for different mechanisms. Arch. Environ. Contam. Toxicol. 40:445-450.

Etheridge, R.D., G.M. Pesti, and E.H. Foster. 1998. A comparison of nitrogen values obtained utilizing the Kjeldahl nitrogen and Dumas combustion methodologies (Leco CNS 2000) on samples typical of an animal nutrition analytical laboratory. Anim. Feed Sci. Technol. 73:21-28.

Ford, C.I., M. Walter, G.L. Northcott, H.J. Di, K.C. Cameron, and T. Trower. 2007. Fungal inoculum properties: Extracellular enzyme expression and pentchlorophenol removal by New Zealand Trametes species in contaminated field soils. J. Environ. Qual. (in press).

Gianfreda, L., F. Xu, and J.-M. Bollag. 1999. Review of laccases: A useful group of oxidoreductive enzymes. Biorem. J. 3:1-25.

Laine, M.M., and K.S. Jorgensen. 1996. Straw compost and bioremediated soil as inocula for the bioremediation of chlorophenol-contaminated soil. Appl. Environ. Microbiol. 62:1507-1513.

Laine, M.M., and K.S. Jorgensen. 1997. Effective and safe composting of chlorophenol-contaminated soil. Environ. Sci. Technol. 31:371-378.

Lamar, R.T., M.W. Davis, D.M. Dietrich, and J.A. Glaser. 1993a. Treatment of a pentachlorophenol and creosote contaminated soil using the lignindegrading fungus Phanerochaete sordida: A field demonstration. Soil Biol. Biochem. 26:1603-1611.

Lamar, R.T., and D.M. Dietrich. 1990a. Use of lignin-degrading fungi in the disposal of pentachlorophenol treated wood. J. Ind. Microbiol. 9:181-191.

Lamar, R.T., and D.M. Dietrich. 1990b. In situ depletion of pentachlorophenol from contaminated soil by Phanerochaete spp. Appl.
Environ. Microbiol. 56:3093-3100.

Lamar, R.T., J.W. Evans, and J.A. Glaser. 1993b. Solid phase treatment of pentachlorophenol contaminated soil using lignin-degrading fungi. Environ. Sci. Technol. 27:2566-2571.

Lamar, R.T., J.A. Glaser, and T. Kent Kirk. 1990. Fate of pentachlorophenol (PCP) in sterile soils inoculated with the white-rot basidomycete Phanerochaete chrysosporium: Mineralisation volatilisation and depletion of PCP. Soil Biol. Biochem. 22:433-440.

Leštan, D., and R.T. Lamar. 1996. Development of fungal inocula for bioaugmentation of contaminated soils. Appl. Environ. Microbiol. 62:2045-2052.

Leštan, D., M. Leštan, J.A. Chapelle, and R.T. Lamar. 1996. Biological potential of fungal inocula for bioaugmentation of contaminated soils. J. Ind. Microbiol. 16:286-294.

Luthy, R.G., G.R. Aiken, M.L. Brusseau, S.D. Cunningham, P.M. Gschwend, J.J. Pignatello, M. Reinhard, S.J. Traina, W.J. Weber, and J.C. Westall. 1997. Sequestration of hydrophobic organic contaminants by geosorbents. Environ. Sci. Technol. 31:3341-3347.

Morgan, P., S.A. Lee, S.T. Lewis, A.N. Sheppard, and R.J. Watkinson. 1993. Growth and biodegradation by white rot fungi inoculated into soil. Soil Biol. Biochem. 25:279-287.

Nadebaum, P., J. Gifford, and A. Bingham. 1992. New Zealand national task group on site contamination from the use of timber treatment chemicals: Pentachlorophenol risk assessment pilot study. Camp Scott Furphy, Melbourne.

Northcott, G.L., and K.C. Jones. 2000. Experimental approaches and analytical techniques for determining organic compound bound residues in soil and sediment. Environ. Pollut. 108:19-43.

NTP. 1999. Technical report-483 (abstract): Toxicology and carcinogenesis studies of pentachlorophenol (CAS NO. 87-86-5) in F344/N rats (feed studies). National Inst. of Environmental Health Services (NIEHS).

Okeke, B.C., A. Paterson, J.E. Smith, and I.A. WatsonCraik. 1997. Comparative biotransformation of pentachlorophenol in soils by solid substrate cultures of Lentinula edodes. Appl. Microbiol. Biotechnol. 48:563-569.

Payne, R., D. Baird, D. Murray, S. Harding, D. Soutar, and P. Lane. 2004. Genstat 7.2 for Windows. Release 7.2. Lawes Agricultural Trust (Rothamsted Experimental Station), Cambridge, UK.

Rost, H., A.P. Loibner, M. Hasinger, R. Braun, and O.H.J. Szolar. 2002. Behavior of PAHs during cold storage of historically contaminated soil samples. Chemosphere 49:1239-1246.

Roy-Arcand, L., and F.S. Archibald. 1991. Direct dechlorination of chlorophenolic compounds by laccases from Trametes (Coriolus) versicolor. Enzyme Microb. Technol. 13:194-203.

Rüttimann-Johnson, C., and R.T. Lamar. 1996. Polymerization of pentachlorophenol and ferulic acid by fungal extracellular lignindegrading enzymes. Appl. Environ. Microbiol. 62:3890-3893.

Rüttimann-Johnson, C., and R.T. Lamar. 1997. Binding of pentachlorophenol to humic substances in soil by the action of whiterot fungi. Soil Biol. Biochem. 29:1143-1148.

Sazbo, M. 1993. New Zealand's poisoned paradise. New Scientist 139:29-33.

Tuomela, M., M. Lyytikainen, P. Oivanen, and A. Hatakka. 1999. Mineralisation and conversion of pentachlorophenol (PCP) in soil inoculated with the white-rot fungus Trametes versicolor. Soil Biol. Biochem. 31:65-74.

Walter, M., L. Boul, R. Chong, and C. Ford. 2004. Growth substrate selection and biodegradation of PCP by New Zealand white-rot fungi. J. Environ. Manage. 71:361-369.

Walter, M., K.S.H. Boyd-Wilson, D. McNaughton, and G. Northcott. 2005a. Laboratory trials on the bioremediation of aged pentachlorophenol residues. Int. Biodeterior. Biodegrad. 55:121-130.

Walter, M., C.I. Ford, J.V. Guthrie, K.S.H. Boyd-Wilson, H.J. Di, K.C. Cameron, and E. Parker. 2007. Bioremediation of aged pentachlorophenol residues by white-rot fungi. p. 18-54. In M.K. Rai (ed.) Mycotechnology: Current status and future prospects. International Publishing House Pvt. Ltd., New Delhi.

Walter, M., J. Guthrie, S. Sivakumaran, E. Parker, A. Slade, D. McNaughton, and K.S.H. Boyd-Wilson. 2003. Screening of New Zealand native white-rot isolates for PCP degradation. Biorem. J. 7:119-128.

Walter, M., K.S.H. Boyd-Wilson, L. Boul, C. Ford, D. McFadden, B. Chong, and J. Pinfold. 2005b. Field-scale bioremediation of pentachlorophenol by Trametes versicolor. Int. Biodeterior. Biodegrad. 56:51-57. 